\title{
Migración, memoria y tikun olam en la obra de la artista judeo-argentina Mirta Kupferminc ${ }^{1}$
}

Migration, memory and tikkun olam in the work of Jewish artist Kupferminc Argentina

Tamara Kohn

Buenos Aires, Argentina

tammykohn@gmail.com

Argentina

\section{Resumen}

Este trabajo tiene como propósito examinar los conceptos de migración, memoria y tikun olam (reparación del mundo) en la obra de la artista plástica Mirta Kupferminc, considerando lo que implica el concepto de identidad en la postmodernidad y en el contexto de la cultura judeoargentina. Estos conceptos son identificados como pilares que sostienen la obra de la artista y que se nutren de sus múltiples identidades. Por medio de ellos se puede explicar como "lo argentino" y "lo judío" interactúan en la obra, tomando las ventajas de la simultaneidad y multiplicidad que permite el medio visual.

Palabras Clave: Migración - Memoria - Tikún Olam - Arte Judío - Kupferminc

\section{Abstract}

The purpose of this paper is to examine the concepts of migration, memory and tikkun olam (fixing of the world) in the work of the argentine artist Mirta Kupferminc, in the context of the Argentine-Jewish culture. These concepts are identified as the pillars that support the artist's work and draw on multiple and complimentary identities. Through the study of the ideas of migration, memory and tikkun olam as expressed in M. Kupferminc's works it is possible to express how the national (Argentine) identity and the Jewishness interact on the canvases, taking advantage of the simultaneity and multiplicity facilitated by the visual medium.

Keywords: Migration - Memory - Tikkun Olam - Jewish Art - Kupferminc 
Durante las últimas dos décadas, fue posible observar una creciente tendencia entre historiadores del arte israelíes, europeos y norteamericanos, a estudiar diferentes expresiones de identidad judía en la obra y vida de artistas judíos. Luego de una lucha histórica de los historiadores del arte judío para establecer la disciplina de Historia del Arte dentro de los Estudios Judaicos, y el Arte Judío dentro de la disciplina de Historia del Arte, los académicos fueron finalmente capaces de centrarse en la definición del arte judío. Por ejemplo Catherine Soussloff señala que desde 1996 el arte judío tiene su propia sesión en las conferencias de la College Art Association. ${ }^{2} \mathrm{Y}$ desde entonces la definición del arte judío fue explorada, en muchos casos, a través del estudio de las expresiones de la experiencia judía en las artes visuales.

La mayoría de los historiadores del arte judío moderno y contemporáneo se refieren hoy a la "experiencia judía" y la "identidad judía" como principales conceptos para definir la expresión de judeidad en las artes visuales. Considerando que la existencia de un "arte judío" ya no resulta una preocupación central. La pregunta pasa a ser ¿qué es la identidad y experiencia judía en el contexto de las artes visuales?

Matthew Baigell y Milly Heyd, compiladores de "Complex Identities: Jewish Consciousness in Modern Art", explican que, "By Jewish art, the coeditors mean an art created by Jewish artists, in which one can find some aspect of the Jewish experience, whether religious, cultural, social or personal" (Baigell y Heyd, 2001, xiv). Por lo tanto, el título del libro "Complex Identities" "denotes the varieties of complementary and conflicting identities within Jewish cultures and national cultures" (Baigell y Heyd, 2001, xiv). El enfoque que ofrecen Baigell y Heyd refleja la dificultad que encontramos en la definición de los límites de una experiencia judía e implica que "lo judío" es parte de una identidad compleja, la cual suele estar en conflicto e interactuar con otras identidades complementarias (culturales y nacionales). 
Partiendo de este enfoque, nos proponemos analizar el rol y el lugar de la identidad judía en su interacción con otras identidades que informan la obra de la artista. Con este fin, observaremos la obra de la artista judía argentina Mirta Kupferminc, en el contexto de su propia cultura, y consideraremos cuáles son las identidades complementarias que afectan y se ven afectadas por su experiencia judía.

Antes, me gustaría mencionar una característica particular de las artes visuales a tener en cuenta al discutir este tema: a diferencia de la literatura, el teatro e incluso el cine, las artes visuales o plásticas, como la pintura y la fotografía, son espaciales y estáticas. Es decir que no es necesario para el artista en cuestión, traducir una experiencia compleja a un lenguaje que requiera un orden temporal y lineal para ser comprendido. El lenguaje visual es diferente en cuanto a que se construye por medio de símbolos que aparecen simultáneamente en el medio en el que se expresan. Esto le permite al artista manipular (consciente e inconscientemente) la expresión de su experiencia en el mundo, jugar con la simultaneidad y la multiplicidad evitando la necesidad de imponer jerarquías entre sus diferentes identidades. Podemos entender esta cualidad de las artes visuales como una forma de expresar la descentralización y el pluralismo, dos elementos centrales de la vida en el mundo contemporáneo. Aclaradas estas ideas, enfoquémonos ahora en el caso particular de Mirta Kupferminc con el fin de entender cómo estos elementos se reflejan en su obra.

\section{Mirta Kupferminc}

Mirta Kupferminc nació en Buenos Aires en 1955, hija de padre polaco y madre húngara, ambos sobrevivientes de Auschwitz que emigraron a la Argentina en 1948. Debido a la condición de sobrevivientes del Holocausto de sus padres, la artista creció sin fotos ni objetos que hayan pertenecido a sus padres antes de su llegada a Buenos Aires. 
A lo largo de su carrera como artista, Kupferminc recibió premios nacionales e internacionales, representó a la Argentina en varias bienales y expuso en museos y galerías tanto judíos como no judíos, en su país de origen y en el extranjero.

A partir de esta breve y resumida biografía podemos observar que la identidad compleja de Mirta Kupferminc está formada por la experiencia de ser judía, argentina, mujer, hija de inmigrantes y sobrevivientes del holocausto, así como por la experiencia de ser artista. $Y$ en efecto, todas estas experiencias son expresadas en su obra. Este argumento es reforzado por la misma artista, quien en una entrevista en 2010 sostuvo que "ser un artista es hacer lo que uno es." ${ }^{3}$ En nuestro caso, nos centraremos en la experiencia como artista judía y nos preguntamos si podemos inferir que ser una artista judía es hacer arte judío. ${ }^{4}$

En los ejemplos a continuación podremos observar tres conceptos centrales relacionados con la experiencia judía por medio de los cuales la artista expresa este aspecto de su identidad incluso al abordar temas que no están directamente relacionados con contenidos judaicos, y que sin embargo se informan de la experiencia de ser judía.

\section{Migración}

El primer concepto que encontramos es el de migración, tema central de un proyecto de la artista titulado originalmente en inglés "Nowhere - Now Here". El proyecto consiste en una serie de fotografías que registran el movimiento de Mirta Kupferminc alrededor del mundo durante un año y medio, con la característica particular de que cada fotografía incluye la anterior, de manera que se acumulan las diferentes fotos, una dentro de otra hasta que en un momento determinado la primera en la serie no se puede ver pero el espectador sabe que esta ahí. En la presentación del proyecto "Nowhere - Now Here" en la Universidad de Maryland en Octubre de 2010, la artista se refirió a la migración como "el movimiento del sujeto en el planeta," ${ }^{5}$ una definición universal y 
suficientemente amplia del concepto que refleja varios elementos de su identidad compleja como artista y judía (entre otros).

Al observar una selección de fotografías de este proyecto vemos imágenes relacionadas con la migración según la definición de la artista. La primera imagen en la serie es el taller de Mirta Kupferminc, le sigue el Aeropuerto Internacional Ezeiza, y luego en otro ejemplo vemos el puerto de La Boca en Buenos Aires. Ejemplos menos explícitos, y sin embargo relacionados con la migración, aparecen en otras fotografías del proyecto como una marcha por el 24 de marzo (día de la memoria en Argentina) seguida por una cena del seder de Pesaj, que conmemora la liberación de los judíos de Egipto, según el relato bíblico (Imagen 1).

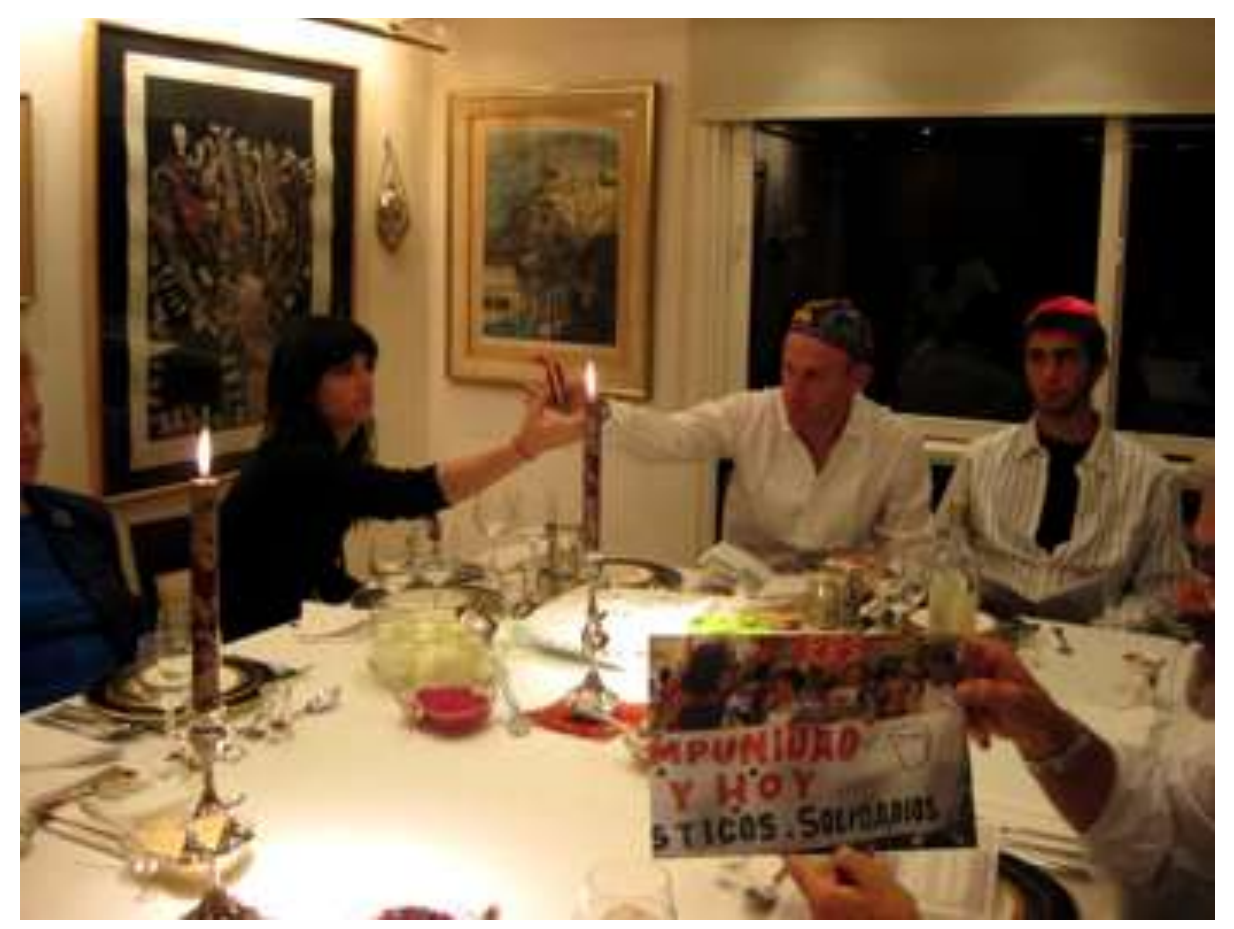

Mirta Kupferminc. "La anterior foto en una cena de "Seder de Pesaj" (Pascuas judías, en donde se recuerda el éxodo de Egipto)" Nowhere, Now Here. Fotografía digital, c. 2010, cortesía de la artista.

Al observar las fotografías en serie, una dentro de otra, como en el último de los casos, vemos la interacción de las identidades de la artista, su complejidad y su expresión simultánea. En la fotografía del Seder de Pesaj, la artista elige un momento de reunión familiar y festejo de la libertad que contrasta con la foto anterior en la serie, la marcha del 24 de marzo, en la que se 
reclama justicia y se hace memoria. La familia sentada alrededor de la mesa sobre la que se observan los diferentes elementos representativos de esta festividad según la tradición judía, representan la identidad judía. La fotografía anterior en primer plano, es un claro símbolo de la reciente y triste historia argentina. Por último en el fondo de la imagen, aparecen los cuadros de la mismísima Kupferminc colgados en las paredes del ambiente en el que tiene lugar la cena de Pesaj. Éstos, podríamos concluir, representan la identidad como artista plástica de Kupferminc.

El tema de la migración no es reciente en la obra de Kupferminc, sino que en su iconografía personal podemos encontrar varios motivos que simbolizan esa idea tal como lo define la artista. Uno de ellos es un grupo de personajes imaginarios a quienes Mirta Kupferminc se refiere como sus "fantasmas." Los "fantasmas" aparecen una y otra vez como Laura Kruger los caracterizó: "desfiles de figuras que rodean la imagen central en sus obras" (Kruger, 2009, p.6). Estas criaturas son producto de la imaginación de la artista. Aparecen por ejemplo en la litografía titulada En camino (Imagen 2), en la que observamos a los personajes cargando árboles desde sus raíces.

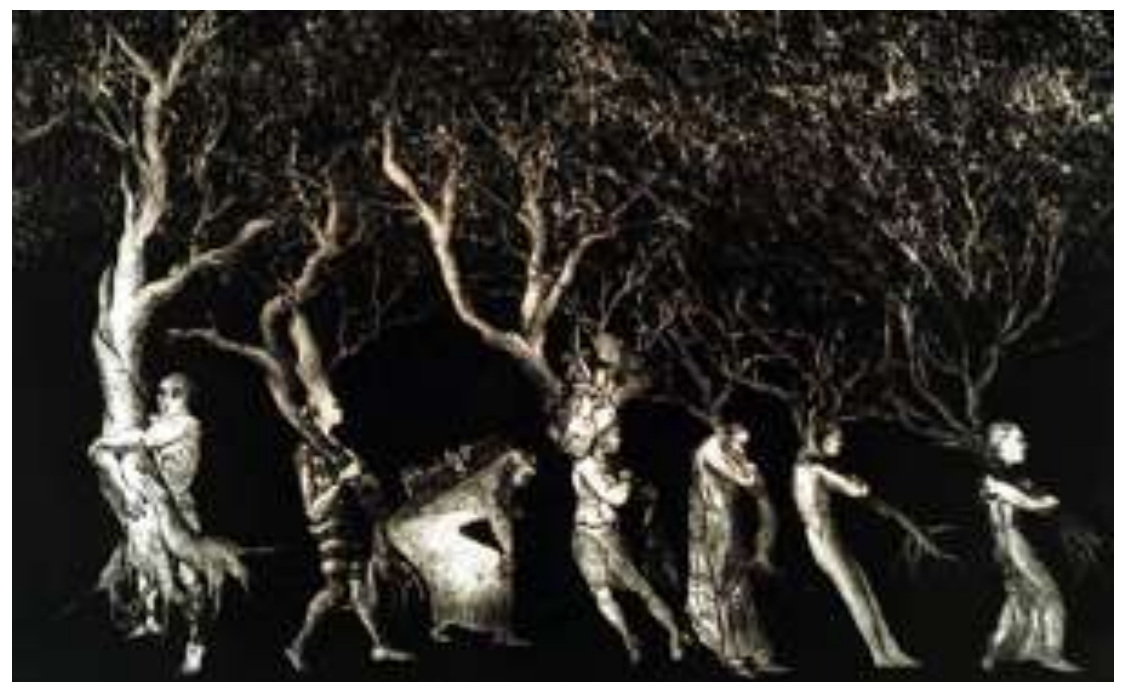

Mirta Kupferminc. On the Way. Etching, $40 \mathrm{~cm}$ x $64 \mathrm{~cm}$. Buenos Aires, 2001. Cortesía de la artista.

Tal como lo explican Marianne Hirsch y Leo Spitzer en un artículo sobre Kupferminc, estos personajes "son pobladores del trabajo de una artista que por sí misma acarrea una historia de 
exilio y desplazamiento" (Hirsch y Spitzer, 2009, p.13). Laura Kruger, asocia los personajes con las culturas nativas latinoamericanas (Kruger, 2009, p.6). En cuanto Hirsch y Spitzer sostienen que "Hija de sobrevivientes europeos del Holocausto creciendo en America Latina durante períodos de dictadura, comparte su bagaje con sus personajes" (Hirsch y Spitzer, 2009, p.13), quienes cargan con la historia del sufrimiento de los judíos así como también con el terror en Argentina.

Los "fantasmas" aparecen en obras como Mi muñeca, sólo una (2004), Fantasías de viaje (1999) y Fuera del Edén (2002). A veces cargan árboles, a veces otros objetos como bibliotecas, letras, sillas, instrumentos musicales y valijas. Siguiendo la línea de análisis de Spitzer y Hirsch podemos decir que cargan las experiencias de la artista, pero además se encuentran en movimiento constante, lo que nos lleva nuevamente a la idea de migración.

La migración es un elemento central en la historia del pueblo judío, en su cultura e incluso en la religión. Desde el éxodo en Egipto hasta la inmigración organizada a Israel, pasando por las persecuciones de los judíos a lo largo de la historia y la necesidad de encontrar un lugar más seguro donde vivir en la diáspora, la migración siempre fue y aún es, uno de los aspectos más significativos de a experiencia judía individual y colectiva. En el caso de Mirta Kupferminc, los fantasmas llevan con ellos en parte, la experiencia de la migración judía.

Esta idea también aparece en algunas de las sillas intervenidas por la artista. Usando sillas abandonadas, Mirta Kupferminc las transforma incorporándole elementos de su vida. Como explica la artista, las sillas representan estabilidad y asentamiento por un lado, pero tienen alas por el otro, lo cual connota movimiento. Sin embargo las sillas con alas no expresan aislamiento, sino que transmiten un sentido de individualidad y pertenencia. ${ }^{6}$ 
En otra obra, Kupferminc ilustra la parasha (porción de la Torá) Beshalaj (imagen 3aㅗ y 3b).

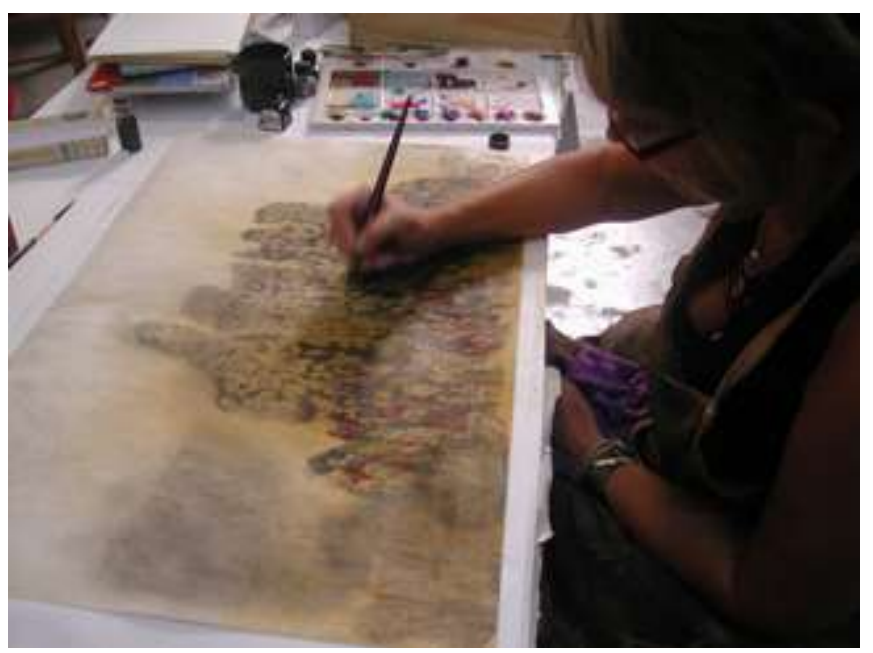

Mirta Kupfemrinc. Beshalach (Women of the Book project). India ink, transfer and oil on parchment. Buenos Aires. En el sitio web Women of the Book:

http://womenofthebook.org/i/1440/beshalach.png

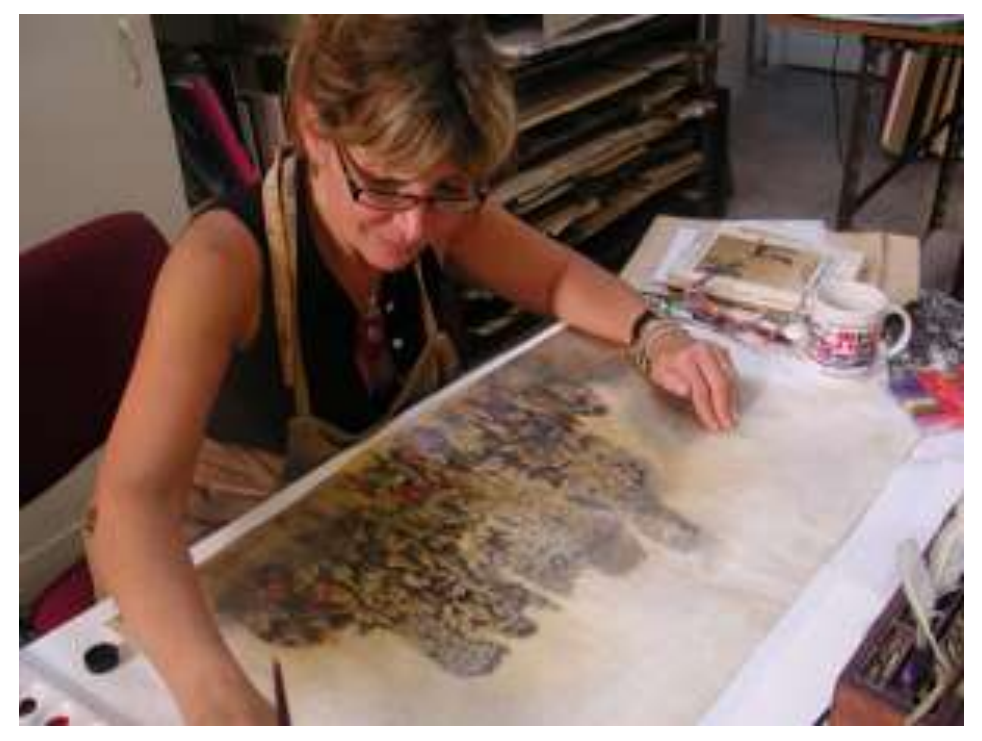

En este trabajo la artista representa a los hijos de Israel en el Éxodo de Egipto, preparándose para recibir la Torá y conformarse como pueblo. Sobre esta obra la artista escribió:

Many felt confident and others wanted to return. You will see that not all of them are looking to the same direction, and you will easily find some that are looking back and others still full of faith in their decision to leave. I have also tried to represent both individuality and belonging (M. Kupferminc, "Parashat Beshalach," Women of the Book, sitio web). 
Aquí la migración representa la idea de individualidad y pertenencia que también encontramos en los personajes errantes y en las sillas personalizadas.

La obra Beshalaj forma parte de un proyecto internacional llamado "Women of the Book" (Mujeres del libro). En este proyecto mujeres artistas judías se unen para celebrar su experiencia judía como mujeres artistas ilustrando las 54 porciones de la Torá de acuerdo con la tradición judía, desde la perspectiva de sus vidas en el siglo XXI. Las "mujeres del libro" tienen un denominador común pero cada una de ellas proviene de un entorno diferente. Kupferminc trabaja junto a artistas norteamericanas, israelíes y europeas, ella es Argentina.

Por último, podemos observar la idea de migración como el movimiento geográfico del sujeto en el "artista diaspórico" en el sentido del legado de R.B. Kitaj. De acuerdo con Kitaj, "The Diasporist lives and paints in two or more societies at once...." (Sander Gilman, 2003, p.223). El legado del "diasporismo" de Kitaj aparece, posiblemente, en la obra Dialogo y Confrontación (imagen 4) de Kupferminc.

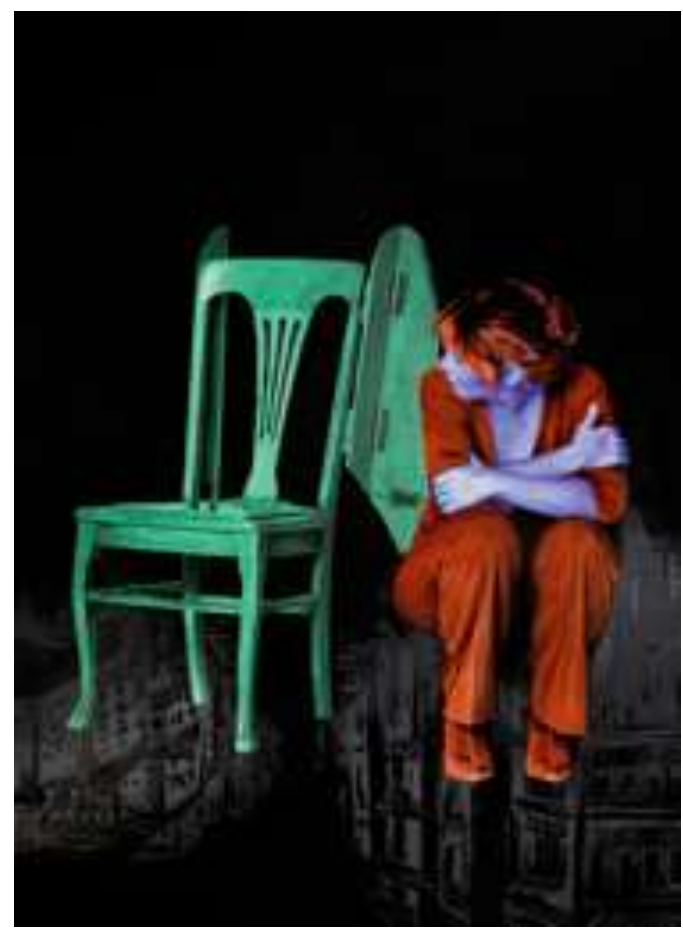

En esta obra la artista aparece junto a su silla con alas. El autorretrato está pintado en óleo, en la tradicional técnica del hiperrealismo, mientras que la silla es una fotografía digital. Podemos observar la tensión entre el presente y el pasado, entre la vida real y la representación en el arte. ${ }^{7}$

Kupferminc. Dialogue and Confrontation. Mixed media on canvas, 200 x $150 \mathrm{~cm}$. Buenos Aires, 2009. Cortesía de la artista. 
De acuerdo con el historiador Sander Gilman, existe una generación de artistas más jóvenes que Kitaj en una diáspora norteamericana, quienes comparten la fascinación de Kitaj por la identidad judía. En el caso de estos artistas, según Gilman, no podemos hablar de influencia, sino de una respuesta comunitaria colectiva a cuestiones específicas relacionadas con la identidad judía luego de la Shoá. ${ }^{8}$ El tema del Holocausto y el compromiso colectivo nos lleva a la discusión sobre el concepto de memoria, el segundo tema central en el arte de Mirta Kupferminc.

\section{Memoria}

Como hija de sobrevivientes de Auschwitz, Mirta Kupferminc creció abrazada por un testimonio visual de la Shoá: los números tatuados en los brazos de sus padres. Kupferminc es testigo de testigos, y como tal, el valor de la memoria surge de la experiencia judía de sus padres e informa el enfoque hacia la memoria en otros eventos de su vida como Argentina.

Además, el concepto de memoria esta conectado con la esencia de las artes visuales. El medio permite la continuidad y la conmemoración perpetua. A su vez, el espectador se convierte también en testigo.

Veamos por ejemplo la obra titulada Embroidered onto my Skin (imagen 5), una fotografía de la mano de Kupferminc bordada con el numero de prisionera de su madre.

Por un lado vemos la expresión de la memoria del Holocausto, pero por el otro, vemos el legado de la cultura húngara por medio del arte del bordado. Además no es el brazo ni la cara que la artista eligió para expresar estos

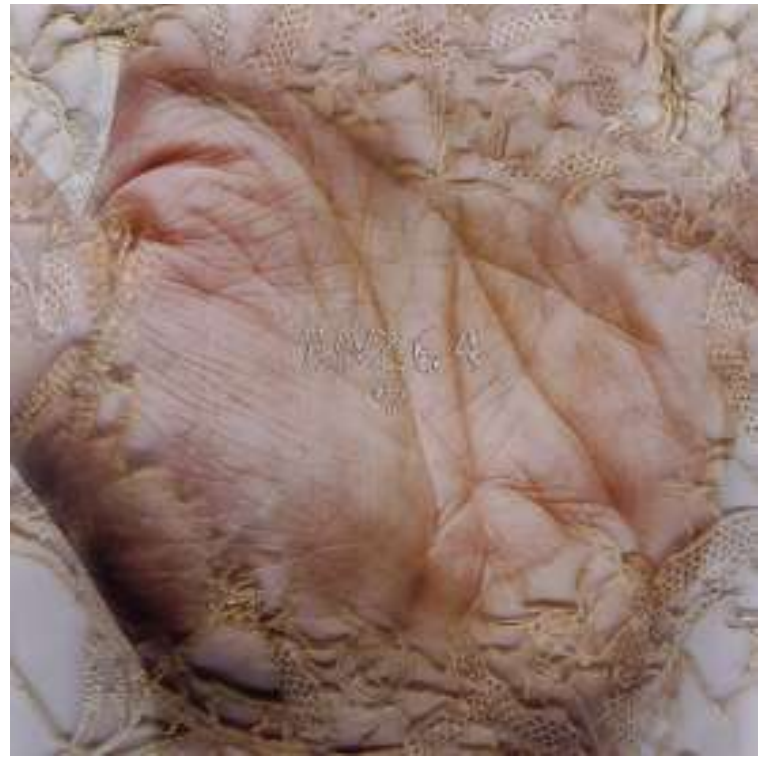

Mirta Kupferminc. Embroidered onto my Skin. Embroidered photograph, $40 \mathrm{~cm} \times 40 \mathrm{~cm}$. Buenos Aires, 2009. Cortesía de la artista. 
aspectos de su identidad, sino la mano, la principal herramienta de trabajo del artista. La expresión de su identidad compleja como artista, hija de sobrevivientes de Auschwitz y de ascendencia húngara ocurre simultáneamente. Las manos se repiten en la obra de Kupferminc al menos tres veces más en Embroidered on my Skin en la que se ven las flores típicas de los bordados húngaros bordadas en la fotografía de la mano, The Map que representa el movimiento migratorio de las ciudades de origen de los padres de Kupferminc hasta Buenos Aires, y The Line of the Heart que ilustra un obelisco bordado, símbolo de Buenos Aires y la palabra "corazón" bordadas también sobre una fotografía de la mano de la artista. Todos estos son autorretratos que refieren simultáneamente a la experiencia como artista judeo-argentina hija de inmigrantes sobrevivientes del Holocausto.

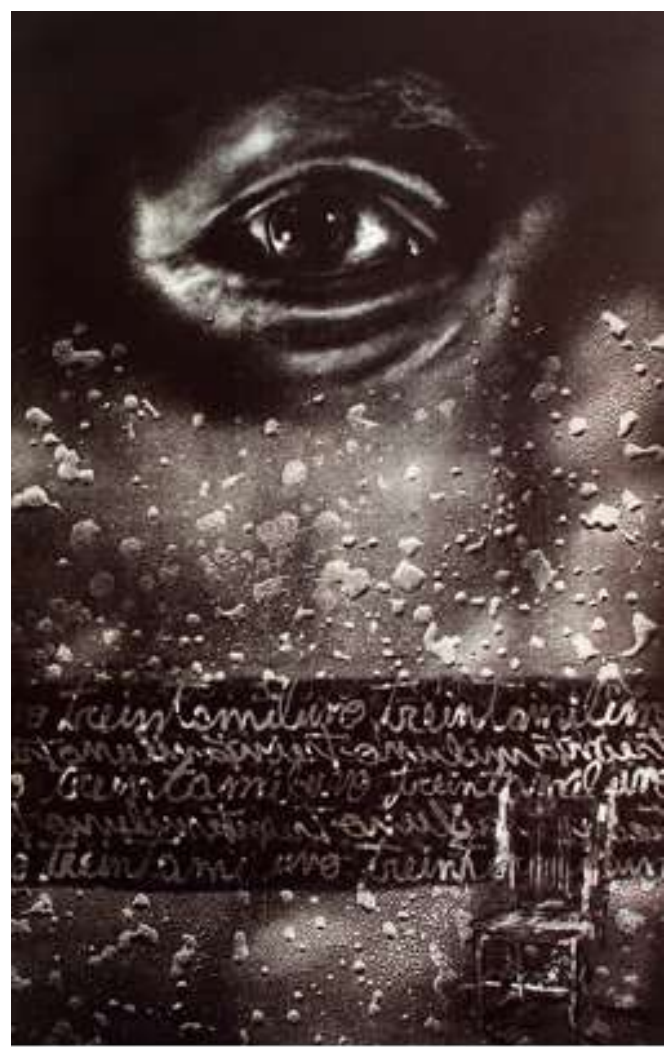

Mirta Kupferminc. Thirtythousandandone. Etching mezzotint, $99 \mathrm{~cm} \times 70 \mathrm{~cm}$. Buenos Aires, 2005. Cortesía de la artista.
La mano bordada evoca el número tatuado. Dora Apel, en Memory Effects: The Holocaust and the Art of Secondary Witnessing, analiza justamente la idea del "judío tatuado" en el arte norteamericano. Kupferminc también aborda la cuestión del uso ornamental del tatuaje en las sociedades contemporáneas y su relación con la Shoá. Las manos bordadas son una proyección de su identidad como "judía tatuada." En su caso, con la experiencia de sus padres durante el holocausto y por la herencia de la cultura húngara.

Mirta Kupferminc no solo aborda la memoria en el contexto del Holocausto sino también conmemora otros genocidios que la identifican como una artista argentina contemporánea. En el grabado Treintamiluno (imagen 
6) Kupferminc perpetúa la memoria de los treinta mil desaparecidos durante la última dictadura militar en Argentina.

La forma en la que la artista aborda la individualización de las víctimas por medio del título de la obra refleja una influencia consciente o inconsciente de la cultura de la memoria en la tradición judía. El titulo de la obra Treintamiluno sugiere la necesidad de la artista de agregar "uno" para individualizar la conmemoración de las víctimas del genocidio. En la parte inferior de la obra hay una imagen de la silla con alas. La misma silla que aparece en la iconografía personal de la artista y representa la migración. Podemos entender que los "desaparecidos," lejos de estar enterrados fueron "desvanecidos en el aire," y la silla vacía con alas nos permite recordarlos. En la parte superior de la misma obra vemos un ojo. El ojo abierto representa la idea del observador, de ser testigo. El rol de testigo también es central en la tradición judía.

El ojo testigo es también utilizado como un símbolo de la conexión con el cosmos y el universo. Hay un sentido místico en la obra de Mirta Kupferminc y su forma de representar el mundo. Esto nos lleva al concepto de Tikkun Olam.

\section{Tikkun Olam}

El arte de Mirta Kupferminc trasmite un sentido de vida por medio de la invocación del misticismo. Toda su obra esta conectada como una red en la que el yo se refleja como un microcosmos. Tomando al ojo como punto de partida, podemos observar la conexión entre el testimonio (witnessing), la fe y la perpetuación de la memoria como una respuesta a las tragedias que ocurren en el mundo contemporáneo.

Uno de los proyectos de Kupferminc fue la creación del libro "Borges y la Kabalá" junto a Saul Sosnowski. El libro consiste en un libro de bibliofilia realizado íntegramente a mano con veintinueve grabados y textos de Saul Sosnowski. Los veinticinco ejemplares contienen además, 
citas cabalísticas y citas de Borges. Borges es un símbolo de la cultura Argentina y la Kabalá es un símbolo de la mística judía. Kupferminc y Sosnowski evocan su identidad judeo-argentina por medio de su respuesta a la obra de Borges.

El libro, el proyecto final, se convierte en un testimonio visual eterno de un proceso de creación que experimenta la artista. Sin embargo, la obra no es estática, sino que es re-significada y continúa transformándose de acuerdo al lector que interactúa con la obra. Durante este proceso aparecen diferentes facetas de su identidad en cada instancia del proceso creativo: hay un estudio de la literatura y cultura Argentina por medio de Borges, al mismo tiempo que la artista se conecta con su identidad judía y se forma como soferet (escriba) para la realización del libro; y por último, hay un sentido profundo de espiritualidad y conexión con el cosmos al crear un libro original y que expresa al mismo tiempo "lo judío" y "lo argentino" por medio de una experiencia artística.

La idea de creación, está también presente en la iconografía de la artista. Mirta Kupferminc incorpora letras hebreas en sus creaciones. Estas tienen un significado místico: en La corona (imagen 7) se observa la figura del rostro humano coronada por las veintidós letras del

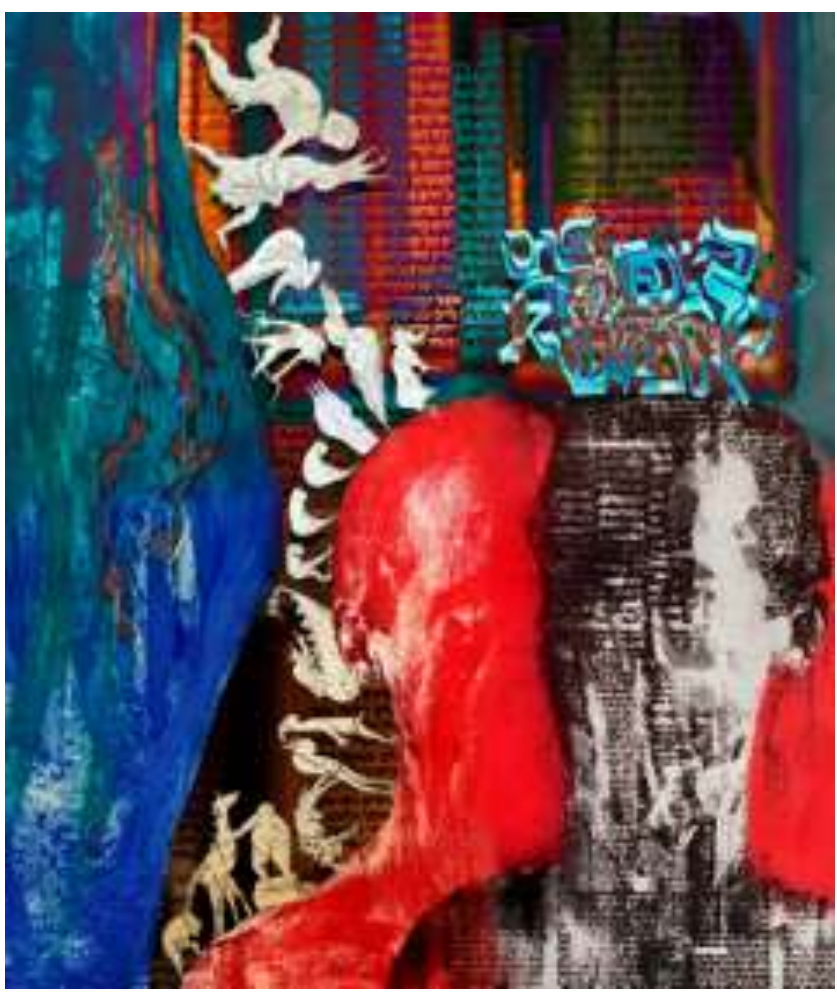

Mirta Kupferminc. The Crown. Digital print, $25 \mathrm{~cm} \times 46 \mathrm{~cm}$. Buenos Aires, 2008. Cortesía de la artista. alfabeto hebreo. 
De acuerdo con la tradición judía la creación del mundo fue coronada con la creación de hombre en el sexto día. Sin embargo, la cabeza que aparece en La corona no tiene una única identidad. Nos recuerda la palabra hebrea para rostro, panim, que es en plural. Además, la corona es la más alta de las sefirot según la tradición kabalística. ${ }^{9}$

El enfoque múltiple que pudimos ver anteriormente en los temas de migración y memoria, aparece también en la expresión de la tradición mística judía en la obra de Kupferminc. Es así como la cultura argentina despierta el interés en los conceptos cabalísticos de la tradición judía y al mismo tiempo éstos inspiran la creación artística. En efecto, el concepto de tikkun olam es central en el trabajo de Kupferminc, al igual que en otros artistas judíos de la era post-Shoá.

En una investigación del arte judío post-Holocausto en Norteamérica, Matthew Baigell encuentra una recurrente alusión a la idea de tikun olam en artistas judíos norteamericanos. Baigell explica que "in cabalistic literature, the concept of tikkun olam marks the final stage of the creation of the universe and assigns the role of responsibility to people. During the creation itself, cosmic disturbances occurred... As result... people are responsible for restoring harmony, striving for the perfection of the world..." (Baigell, 1997, pp. 54-55)

Baigell menciona diferentes formas en las que los artistas abordan esta idea. Por ejemplo, Renata Stein crea su obra a partir de la unión de piezas rotas de objetos variados; y Mary Kab usa fotografía documental porque "there is a great need, he believes, to reach people, to strengthen their resolve, and to support the social fabric" (Baigell, 1997, p. 57).

En efecto, al sentido tradicional de Tikun Olam, se le suma un sentido que se desprende de la experiencia del Holocausto. ${ }^{10}$ Es decir, que los artistas asumen la responsabilidad de corregir el mundo justamente porque son judíos y porque sienten el compromiso con la memoria. Dejar de luchar por la corrección del mundo, explica M. Baigell parafraseando al artista Galles, "would 
grant Hitler's victory..." (Baigell, 1997, p. 57). Esta victoria ocurriría si el pueblo judío dejara de testificar la posibilidad de transformar el mundo.

De manera similar a los artistas estudiados por M. Baigell, Mirta Kupferminc trabaja con sillas y otros objetos abandonados. M. Baigell observa que cuando se trata de la cuestión del Holocausto hay un sentido adicional del concepto de tikun olam. Éste tiene un significado judío y social que demuestra el compromiso social y colectivo. Estos son también experimentados por Kupferminc y expresados en su arte. Por ejemplo, cuando se le preguntó a la artista sobre el concepto de tikun olam, Kupferminc explicó que "dando todo lo que somos con total honestidad en lo que hacemos, se logra corregir el mundo."11

\section{Conclusión}

Mediante el estudio de la obra de Mirta Kupferminc pudimos observar cómo las diferentes identidades de la artista informan su trabajo. Con respecto a la interacción de la identidad judía con otras identidades, hemos visto que como hija del siglo XXI, Mirta Kupferminc no lucha contra la individualización. La tensión entre individualidad y pertenencia se equilibra en la expresión de la experiencia personal para cumplir con la misión de reparar el mundo. Lo mismo ocurre con la tensión entre el pasado y el presente y entre la identidad judía y la argentina. El arte de Mirta Kupferminc refleja un ser complejo en el que el proceso creativo es estimulado por una u otra situación, pero siempre están todas las identidades presentes simultáneamente.

Por último, los conceptos de memoria y migración demuestran la auto-consciencia del artista de su propia vida. Esto la lleva a actuar como agente social, reflejando sus propias experiencias en su obra que se convierte en un testimonio visual. La idea de tikun olam es la que transforma a la artista en un individuo comprometido con la sociedad, siempre por medio de su obra que refleja el yo y por lo tanto su identidad compleja. 


\section{Notas}

${ }^{1}$ Este ensayo fue presentado en la XV LAJSA Conference, Arizona State University, Tempe, AZ, 12-14 de Junio, 2011.

${ }^{2}$ Catherine M. Sousslouff, "Introducing Jewish Identity to Art History," en Jewish Identity in Modern Art History, p. 1.

${ }^{3}$ Mirta Kupferminc, entrevista telefónica con la autora, 30 de diciembre de 2010.

${ }^{4}$ Asimismo, con esta misma obra la artista se inserta y se identifica como artista argentina, de manera que su identidad judía también afecta la cultura argentina.

${ }^{5}$ Mirta Kupferminc, “Nowhere Now Here," University of Maryland, Oct. 2010, Conferencia.

${ }^{6}$ Mirta Kupferminc, entrevista telefónica con la autora, 30 de diciembre de 2010.

${ }^{7}$ La misma tensión se observa en la obra Beshalach, donde existe un enfoque contemporáneo hacia la Torá por medio de tinta y transfer sobre pergamino, aludiendo a la tradicional técnica utilizada por los escribas en el judaísmo.

${ }^{8}$ Sander Gilman, “R.B. Kitaj's 'Good Bad' Diasporism and the Body in American Postmodern Art," En: Complex Identities, 2003, p. 224.

${ }^{9}$ Tamara Kohn y Judy Nowominski, "Nota de Tapa," 40.

${ }^{10}$ Sobre el sentido tradicional de tikun olam ver Ana Maria Tapia-Adler, "Letaken ‘Olam: Arreglar el mundo, una tarea humana (Una perspectiva Judaica)"CEJ.

${ }^{11}$ Mirta Kupferminc, entrevista telefónica con la autora, 30 de diciembre de 2010. 


\section{Bibliografía}

APEL Dora. Memory Effects: The Holocaust and the Art of Secondary Witnessing. New

Brunswick, NJ, Ed. Rugters University Press, 2002. 256 p.

BAUMEISTER Roy F. "The Self and Society: Changes, Problems and Opportunities." EN: ROY

Self and Identity: Fundamental Issues. New York y Oxford, Ed. Oxford University Press, 1997. pp. 191-217.

BAIGELL Matthew. Jewish American Artsits and the Holocaust. New Brunswick, NJ, Rugters University Press, 1997. 180 p.

BAIGELL Matthew, HEYD, Milly. Complex Identities: Jewish Consciousness and Modern Art. New Brunswick, NJ, Ed. Rugters University Press, 2001. 301 p.

BRAYLAN Marisa, FEIERSTEIN Daniel, GALANTE Miguel, JMELNIZKY Adrian. Situation of the Jewish Detainees-Disappeared during the Genocide perpetrated in Argentina. Buenos Aires, Social Research DAIA, 2000.

DAVIDSON Aryeh. "Revisiting Jewish Identity and Jewish Education: Psychological

Perspectives." EN: Making a Difference: Jewish Identity and Education. Ed. SCHER D., ZISENWINE, D. Tel Aviv, Tel Aviv University, 1997. pp. 67-77.

GECAS Viktor, and Andrew J. Weigert. "Symbolic Interactionist Reflections on Erikson, Identity, and Postmodernism." Identity 5. No. 2: 161-174.

AA.VV. Wanderings, (exh. cat.). New York, Hebrew Union College-Jewish Institute of Religion Museum, 2009. n.p.

GILMAN Sander. "R.B. Kitaj's 'Good Bad' Diasporism and the Body in American Postmodern Art." EN: M. BAIGELL, M. HEYD (Eds.) Complex Identities: Jewish Consciousness and Modern Art. New Brunswick, NJ, Ed. Rugters University Press, 2001. pp. 223-237.

HIRSCH Marianne y SPITZER Leo. "Las rutas sin raíces de Mirta Kupferminc". EN: AA. VV. Wanderings, (exh. cat.). New York, Hebrew Union College-Jewish Institute of Religion Museum, 2009. s.n. 
KUPFERMINC Mirta. "Artista o artista judio? su singularidad." EN: FEIERSTEIN, R., SADOW, S.A., (Eds.). Recreando la Cultura Judeoargentina: Literatura y Artes Plasticas. Tomo II Buenos Aires, Ed. Mila Ensayos y AMIA, 2003.

KUPFERMINC Mirta. "Nowhere Now Here." Conferencia dictada en la Universad de Maryland. Oct. 2010.

KUPFERMINC Mirta. "Parashat Beshalach.” EN: Sitio web Women of the Book. Link: womenofthebook.org/artists/mirta-kupferminc/ KOHN Tamara., NOWOMINSKI Judy. "Nota de Tapa." Kol Hilel 5771. Septiembre 2010: 40, 2010.

KRUGER Laura, “Mirta Kupferminc: Realismo Mágico.” EN: AA. VV. Wanderings, (exh. cat.). New York, Hebrew Union College-Jewish Institute of Religion Museum, 2009. s.n.

OLIN Margaret. The Nation without Art: Examining Modern Discourses on Jewish Art. Lincoln y London, University of Nebraska Press, 2001. 308 p.

SOUSSLOFF Catherine M., (Ed.). Jewish Identity in Modern Art History. Berkley, California University Press, 1999. 249 p.

TAPIA-ADLER, Ana María. "Letaken ‘olam, arreglar el mundo, una tarea humana (Una perspectiva judaica)." En Religión y Cultura, vol XIV, Volumen Aniversario 30 años del Seminario Interdisciplinario Permanente de profesores "Religión y Cultura" (1978-2008) Facultad de Filosofía y Humanidades, Centro de Estudios Judaicos. 2008. Páginas: 13-26.

\section{Entrevistas:}

KUPFERMINC Mirta. Entrevista telefónica con la autora, 30 de diciembre de 2010. 